\title{
A Dramaturgia no Tempo do "Pós-Dramático"
}

\author{
Joseph Danan \\ Université Sorbonne Nouvelle Paris 3, Paris, França \\ E-mail: joseph.danan@wanadoo.fr \\ Tradução: Clóvis D. Massa \\ Universidade Federal do Rio Grande do Sul \\ E-mail: clovisdmassa@gmail.com
}

\section{Resumo}

Algo está transformando profundamente o teatro. Hans-Thies Lehmann teve o mérito de nomear esse fenômeno, propondo a noção de "teatro pós-dramático" - mesmo que essa expressão seja discutível na medida em que essas novas formas não necessariamente anulam o drama. $O$ teatro do século XX se baseou no paradigma de uma "arte em dois momentos" (Henri Gouhier). O autor escreve uma peça, depois o diretor a pega e a monta. Essa é a utopia de Artaud, a de um "criador único", que parece tomar forma nesse início do século XXI. A dramaturgia se encontra inevitavelmente afetada por essa evolução: obviamente, em seu primeiro sentido, a arte de escrever uma peça, quando a escrita e a encenação ocorrem no mesmo movimento; mas também em seu sentido moderno, quando o termo se aplica à passagem para a cena de uma peça pre-existente. Entre a transformação de uma obra dramática em um material para a cena, sem levar em conta sua estrutura dramática, e a imposição de uma rígida "grade de leitura", ainda deveria haver espaço para uma dramaturgia aberta e sensível, criando as condições de uma experiência para o público.

\section{Palavras-chave}

Dramaturgia. Dramaticidade.

Escrita Dramática. Teatro "Pós-Dramático". Performance. Experiência.
Résumé

Quelque chose est en train de transformer en profondeur le théâtre. HansThies Lehmann a eu le mérite de nommer ce phénomène en avançant la notion de "théâtre postdramatique" - même si cette expression est discutable dans la mesure où ces nouvelles formes n'annulent pas nécessairement le drame. Le théâtre du XXe siècle était basé sur le paradigme d'un "art à deux temps" (Henri Gouhier). L'auteur écrit une pièce, puis le metteur en scène s'en empare et la monte. C'est l'utopie d'Artaud, celle d'un "créateur unique", qui semble prendre corps en ce début de XXle siècle. La dramaturgie se trouve inévitablement affectée par cette évolution : évidemment, dans son premier sens, l'art d'écrire une pièce, lorsque l'écriture et la mise en scène se produisent dans le même mouvement ; mais aussi dans son sens moderne, lorsque le terme s'applique au passage à la scène d'une pièce préexistante. Entre la transformation d'une œuvre dramatique en matériau pour la scène, sans prendre en compte sa structure dramatique, et l'imposition d'une "grille de lecture" rigide, il devrait y avoir encore place pour une dramaturgie ouverte et sensible, créant les conditions d'une expérience pour le public.

\section{Mots-clés}

Dramaturgie. Dramaticité. Ecriture Dramatique. Théâtre "Postdramatique".

Performance. Expérience. 
Algo está mudando, transformando profundamente o teatro e nossa relação com a cena. Um fenômeno de amplitude comparável no mínimo com o surgimento da encenação moderna no final do século XIX. Hans-Thies Lehmann teve o mérito de dar um nome a esse fenômeno, o "teatro pós-dramático", mesmo que esse nome seja questionável, porque o que nasce diante de nossos olhos não anula necessariamente o drama, abrindo, ao contrário, a novas formas de dramaticidade que será necessário tentar identificar e nomear.

Como caracterizar essa alteração? 0 teatro explodiu e ele está, é verdade, dissociado do drama. Muitos espetáculos, hoje, não se baseiam em uma obra dramática prévia e, conseqüentemente, no gesto de quem a encena. Textos não dramáticos são recorrentes (textos narrativos e materiais variados, de ensaios filosóficos ou científicos a cartões postais, de poema a documento jornalístico ou histórico), a escrita nasce do palco (assinada por uma pessoa ou um coletivo), a interdisciplinaridade, que vê coexistir diferentes linguagens - o vídeo, a dança, a música ao vivo, o circo... -, fazendo do texto um material entre outros e removendo seu valor matricial (entendendo por isso: sua capacidade de estar na origem, mas também de gerar um número indefinido de encenações). Mais profundamente, é a própria natureza da representação que se encontra transformada. A influência, em particular, da arte da performance, abalou a mimese, que fundava o teatro ocidental desde Aristóteles.

"O teatro é falso", diz Marina Abramovic, "há uma caixa preta, você paga por um ingresso e olha para alguém que interpreta a vida de outra pessoa. A faca não é real, o sangue não é real e as emoções não são reais. A performance é exatamente o oposto: a faca é real, o sangue é real e as emoções são reais. É um conceito dife- rente. Essa é a verdadeira realidade."1 Ora, essa oposição, a cena contemporânea não deixa de colocar em jogo, procurando não o efeito de real (a ilusão), mas o efeito real. A representação irá então opor com vontade a "presentificação"2, valorizando todo o seu peso e valor ao presente do ato teatral, na presença. Isso significa: uma cena teatral existente por si mesma, no aqui e agora da representação (ou da presentificação), sem procurar criar um outro lugar (outro lugar, outro tempo). O ator também está à nossa frente por si mesmo: um performer que, em casos cada vez mais frequentes, anula qualquer efeito de personagem. "Esses palcos não mostram o mundo. Eles fazem parte do mundo. Esses palcos estão lá simplesmente para nos transportar [...] Você não vê um cenário imitando outra cenário [...] $\mathrm{O}$ tempo que você vive não imita outra tempo" (HANDKE, 1968, p. 22): o "teatro sem ilusão"3, o teatro sem a mimese, é isso em direção ao que parece tender a criação cênica contemporânea, desde o manifesto de Peter Handke, Insulto ao Público (1966), onde, no lugar dos personagens, "quatro atores" compartilham uma fala não indicada.

Eu vejo em uma sequência do Inferno de Romeu Castellucci ${ }^{4}$ o emblema deste teatro. Seres que não são personagens e menos ainda atores (junto aos poucos atores misturam dançarinos, crianças e muitos figurantes) avançam um após o outro para o público e passam a oferecer seus ros-

\footnotetext{
1 Citado por Jacques Magnol, na ocasião da exibição-performance "Marina Abramovic: The Artist is Present", New York, Museum of Modern Art, march-april 2010.

2 Cf. Jean-Frédéric Chevallier, "Le geste théâtral contemporain : entre présentation et symboles", L'Annuaire théâtral. Revue québécoise d'études théâtrales, $n^{\circ}$ 36, automne 2004 ; e "Le geste théâtral contemporain", Frictions, n 10, automne-hiver 2006. (No original, présentation. N. do trad.)

3 Cf. Christian Biet et Pierre Frantz, "Le théâtre sans l'illusion", Critique, n699-700, août-septembre 2005.
}

4 Festival d'Avignon, Cour d'honneur du Palais des Papes, 2008. 
tos e seus corpos. Desenho de um teatro de apresentação e presença, onde nada é representado, nada além dessa amostra da humanidade se apresentando em cena - pela metonímia, se você preferir, da humanidade. ${ }^{5}$ Pois esses teatros não excluem nem o símbolo nem a metáfora, mas esses são secundários, frutos de uma elaboração posterior pelo espectador, tomados sobretudo pelo poder do momento presente. Não é um símbolo de "proposição deliberada", como diz Maeterlinck, ao qual se opõe a um símbolo que "ocorreria sem o conhecimento do poeta e [...] quase sempre iria muito além de seu pensamento". "Não acredito", ele diz novamente, "que o trabaIho possa nascer do símbolo; mas o símbolo sempre nasce da obra se for viável". (MAETERLINCK in HURET, 1982, p. 123)

Havia, no Inferno, outra sequência emblemática: no início do espetáculo, Castelluci vinha ao proscênio, emitia aos espectadores "Eu me chamo Romeo Castellucci", antes de ser equipado com um cinto de proteção e se entregar a cães treinados que o atacavam e o jogavam no chão. Na sequência seguinte, um acrobata escalava a fachada do Palácio dos Papas, em Avignon, para o Pátio Nobre do qual o espetáculo foi concebido. $O$ ataque dos cães era real, Castellucci não interpretava um personagem, e a escalada da fachada do Palácio dos Papas era uma ação real, realizada em tempo real, incompressível. A densidade do real dessas duas ações saturava o espaço-tempo da representação, não deixando entrever nada além do que elas mesmas, em sua realização.

No mesmo espetáculo, um cubo de vidro deixava crianças brincando umas com as outras como em uma creche, sem perceber o olhar dos espectadores, e era como um fragmento retirado do mundo real, sem

5 Cf., sobre essa sequência e sobre esse spectacle, J. Danan, "Témoins d'une présence", Etudes théâtrales, n 51-52 / 2011. a interposição do signo, e colocado como tal em cena pelo jogo de uma colagem. Poder do momento. Poder do real em estado bruto. Poder do vivo, do "ator que não repete o mesmo gesto duas vezes". (ARTAUD, 1964, p. 18) Esta é a utopia de Artaud que parece querer encarnar no início do século XXI em programas como este. ${ }^{6}$

Esses teatros vem dissolver a figura do diretor. Este, em sua relação (construtiva tanto quanto conflituosa) com a do autor (quer dizer o autor dramático), constituía a pedra angular da arte teatral no século XX, baseada nessa dualidade ou nesse acoplamento: o autor escreve uma peça, o diretor, como se dizia, "a apreende" e a monta. Era o paradigma do teatro como "arte em dois tempos." Os grandes "reformadores" do teatro, Craig e Artaud, clamaram, desde as primeiras décadas do século XX, por uma outra figura, então utópica, a de um "Criador único", como designa Artaud, anulando esse dois tempos. É essa figura que se encarna hoje, quer seja sob a forma de um demiurgo (Castellucci, creditado no Inferno pela "encenação", cenografia, iluminação, figurinos e, em parceria com Cindy Van Acker, pela coreografia) ou de um coletivo (como, na França, D'ores et déjà ${ }^{8}$ ou Les Chiens de Navarre ${ }^{9}$, as duas práticas, curiosamente, não sendo contraditórias, o demiurgo operando dentro de uma equipe de colaboradores muitas vezes fieis, o coletivo não relutando em ser guiado por um "diretor", mesmo que o nome possa bem ser inadequado.

A dramaturgia, necessariamente, é afetada por isso. Obviamente, em seu sentido original, uma vez que a "arte da composi-

6 Cf. Isabelle Barbéris, Théâtres contemporains. Mythes et idéologies, PUF, 2010, que coloca a cena contemporânea sob o duplo signo do "mito do real" e do "mito do vivo".

7 Cf. Henri Gouhier, Le Théâtre et les arts à deux temps, Flammarion, 1989.

8 Companhia criada em 2002.

9 Companhia criada em 2005. 
ção de uma peça" terá que ser "a arte da composição de um espetáculo". Esse sentido poderia então bem ser fundido no segundo sentido, uma vez que não se trata mais, nesse tipo de processo, da passagem para a cena de uma peça escrita anteriormente..$^{10}$

A mudança, na realidade, é mais profunda. A dramaturgia estabelecia uma ordem, que colocava em jogo o sentido da obra. A arte teatral do século XX não era estruturada unicamente pelo par autor-diretor ou, para tornar as coisas menos pessoais, pela relação de uma obra dramática e sua encenação, mas por uma tríade: a obra dramática, a encenação, a dramaturgia. O colapso implica de maneira igual e articulada os três termos dessa tríade. Como poderia ser de outra maneira? A dramaturgia não é isolada: ela atravessa a obra dramática assim como a encenação, pois ela é o processo mesmo que vai de uma a outra e as conecta.

Enquanto "organização da ação", ela estava ligada à fábula, que o século XX viu gradualmente enfraquecer, em outras palavras, a ação em sua dimensão mimética. Essa constituía a base do sentido. O fenômeno culminou com Brecht, cujo teatro "épico", longe de constituir o oposto do drama, foi dele o ponto culminante. Foi na década de 1970, no auge da linguística e das ciências humanas, que a dimensão semiológica do teatro foi totalmente apreciada. Tudo era signo e sistema de signos: a obra dramática $e$, ainda mais, a encenação. A partir desse sistema, a dramaturgia se tornou o agente. Tudo tinha que significar. O espectador era um decifrador de sinais, um decodificador.

Essa pode ser a mudança mais radical. O espectador não é mais aquele que, na contemplação mais ou menos ativa diante da obra, procura entendê-la. Arrancado do

10 Sobre os dois significados da palavra "dramaturgia", cf. J. Danan, Qu'est-ce que la dramaturgie ?, Actes Sud - Papiers, "Apprendre", 2010. O que é a dramaturgia? está disponível em português pela Editora Licorne, de Évora (2010). Nota do trad. reino do significado (que pode ser desestabilizador), ele é chamado a viver uma experiência. E a relação que ele é levado a manter com a obra não é fundamentalmente diferente daquela que ele tem com um acontecimento vivido. Não é assim que é preciso compreender o face a face de "Inferno" mencionado acima? Como um encontro, no sentido pleno, entre a cena e o palco, o acontecimento de um encontro, simbolizado um pouco mais distante no espetáculo pelo toldo partido da cena e cobrindo a assembleia de espectadores. O espetáculo inteiro: a travessia de uma experiência. Quanto mais a obra souber instaurar uma relação forte com o espectador, mais ela terá a chance de fazer "sentido" para ele, mas mais tarde em sua vida, pelo trabalho consciente e inconsciente da memória, do mesmo modo que um acontecimento vivido, acabará se encaixando em uma cadeia significativa, assumindo um significado - instável, mudando com o passar dos anos. "No meio do caminho da nossa vida / eu estava perdido em uma floresta escura": essas são as primeiras palavras da Divina Comédia. A obra compromete a vida.

Aqui, em linhas gerais, a descrição da paisagem teatral. Um arquipélago de formas em constante metamorfose, atravessado por múltiplas correntes, no meio do qual vejo emergir duas questões: Como fica, hoje, a dramaturgia quando ela se aplica ainda à passagem para a cena de uma obra dramática preexistente? Como fica, hoje, a escrita dramática? Supõe-se que, em ambos os casos, as transformações da paisagem teatral não possam deixá-la incólume.

Por mais diferentes que sejam as práticas, elas coexistem nessa paisagem, porque é a paisagem de uma época. Entre elas, as fronteiras só podem ser porosas. Concretamente: montar uma obra dramática, clássica ou contemporânea, não se faz fora do contexto que acabamos de descrever. Isso tem 
implicações sobre a encenação. Isso deve ter implicações também sobre a dramaturgia, caso contrário, são os aspectos mais superficiais das novas formas cênicas que prevalecerão: se montará Andrômaca no meio de um show de rock sem saber por que, Romeu e Julieta farão trapézio, a cena será inundada com vídeo, independentemente da peça montada. Práticas cegas e descontroladas, dizia Bernard Dort. (DORT, 1986, p. 8)

Não que a dramaturgia ainda não tenha produzido uma "leitura", no sentido em que se entendia nos anos 1970. Isso seria necessariamente redutor em termos do que devia ser considerado como experiência vivida. Se ditarmos o sentido do que você viveu, não há mais experiência possível. Mas entre a transformação de uma obra dramática em um material ${ }^{11}$, em desafio à dramaturgia interna (sentido 1), que a constitui em sua historicidade, e a "grade da leitura", deveria permanecer o lugar de uma dramaturgia (sentido 2) aberto, sensível, que define as apostas de um trabaIho e cria as condições da experiência.

$\mathrm{O}$ caminho é estreito. $\mathrm{O}$ que fazer com o personagem quando não acreditamos mais no personagem e queremos ver um performer executar em cena uma série de ações que se referem apenas a si mesmas, sem mimese? O que fazer da narração quando contar uma história não evidencia mais a prioridade ao olhar do que acontece em cena, parecendo ser improvisado? Então, não se monta mais nem Andrômaca, nem Romeu e Julieta nem mesmo A Gaivota. Mas se mesmo assim se quiser ainda montá-las - e a mínima coisa é perguntar por que - é preciso encontrar na obra o que fará eco com a linguagem atual da cena e poderá nela se inscrever. Despir o personagem de si mesmo para deixar ver o

11 Sobre a distinção entre peça de teatro e texto-material, cf. também J. Danan, Qu'est-ce que la dramaturgie ?, op. cit. ator como ser, em sua "nudez" existencial"12, fora de qualquer composição. Não tentar criar um "outro mundo", mas acreditar neste, no presente da cena em sua materialidade. Essas certamente são questões de encenação e de direção de ator, mas pertencem à dramaturgia revelar quais serão os riscos da experiência: primeiro para aqueles - os atores - que terão que viver em cena, para que outros tenham a chance de viver na plateia. É nesses termos que abordei em 2004 o trabalho dramatúrgico de Quando despertarmos de entre os mortos de lbsen, dirigido por Alain Bézu ${ }^{13}$. Eis o que escrevi na época, em notas dramatúrgicas para o diretor:

Trata-se de criar um dispositivo para reflexão [...] O espectador faz parte do dispositivo. É ele que, diante da caixa experimental, como na experiência do gato de Schrödinger, decide o indecidível - se o gato está morto ou vivo, o que não deixa de ter ressonância com Quando despertarmos de entre os mortos. Isto não é uma coincidência: essa peça vai ao coração do essencial: a vida, a morte; estamos nós mortos ou vivos? Concretamente, na encenação: parar o menos possível os signos, o significado. Fazer experimentar. Jean-Luc Nancy fala da "experiência do sentido". E exatamente isso: para os atores (e todos os que fazem o espetáculo) e para os espectadores. $\mathrm{O}$ que acontece quando nós despertarmos de entre os mortos? "Nós" designa todos os participantes da experiência: todas as pessoas vivas, das quais os espectadores fazem parte. Vamos experimentar juntos (e cada um por si, na sua solidão: não há comunhão, não é a missa) o tempo da experiência - ou, talvez, é preciso dizer, o tempo de uma série de experiências. Porque esse despertar não é feito de uma só vez. A passagem continua a ser feita, e em todas as direções possíveis. Estranhamente, parece que não há mais

12 Cf. Jean-Luc Nancy, Le Sens du monde, Paris, Galillé, 1993, p. 195.

13 Criação na Scène Nationale de Petit-Quevilly, em janeiro de 2005. . 
do que duas. De qualquer forma, não é uma questão de ressurreição, no sentido cristão (e somente isso, o fato de a passagem não ser unívoca, seria suficiente para anular o significado religioso). $[\ldots]$

O espectador se projeta (mentalmente) no palco da experiência, pois é a sua própria vida, na sua experiência mais essencial, que lhe é dada a experiência. Ele está morto, ele está vivo? Só ele pode decidir isso, se ele pode. $[\ldots]$

O menor efeito possível de personagem. Porque é uma peça na qual há o menos possível de drama e que, portanto, nos coloca mais próximo de "apresentar" do que de "representar". É a modernidade. Entre Rubek e Maja, não há drama. Maja se afasta e se aproxima de Ufheim. Rubek a deixa ir. Entre Rubek e Irene não há (quase) nenhum drama. Há uma série de movimentos que são resolvidos em um grande movimento que os aproxima um do outro e os faz se dirigir para a morte. ${ }^{14}$ Todos estão mais próximos da vida. $\mathrm{Da}$ experiência (prova) da vida. E da reflexão sobre suas vidas - mas essa é secundária em relação ao que eles experimentam no momento. Essa experiência da vida, essa dúvida (essa inquietude) que a acompanha permanentemente é o que aproxima a peça da "presentificar". Para os atores, é preciso estar mais perto dessa vida na nudez do momento, compartilhada com o espectador. (Joseph Danan, Texto dramatúrgico inédito).

Certo, Quando despertarmos de entre os mortos pertence evidentemente a esse novo paradigma do drama que Jean-Pierre Sarrazac chama de "o drama da vida", em oposição ao "drama na vida"15: um drama reduzido ao essencial, o de uma vida inteira. É, no entanto, um questionamento semelhante que nos habitou, Alain Bézu e eu, quando trabalhamos no ano se-

\footnotetext{
14 Cf. Joseph Danan, « Du mouvement comme forme moderne de l'action dans deux pièces d'lbsen », Etudes théâtrales, $\mathrm{n}^{\circ}$ 15-16 / 1999.

15 Cf. Jean-Pierre Sarrazac, Poétique du drame moderne, Seuil, 2012.
}

guinte em $A$ Ilusão Cômica, de Corneille ${ }^{16}$ :

\begin{abstract}
Dizer que tudo é teatro não resolve nada, porque poderíamos dizer: tudo é vida. Tudo tem a aparência, mas também a realidade da vida, pois são atores vivos que compartilham um espaço-tempo conosco durante a duração da performance. É uma troca de experiências que Pridamant é a vítima e o destinatário, a cobaia e o sujeito privilegiado, aquele que invejamos por sua fé no que ele vê (que nós nunca chegamos a esse ponto). A maior parte da encenação pode muito bem compartilhar (tanto quanto possível) essa fé. (CORNEILLE; DANAN, 2006, p. 200)
\end{abstract}

Mesmo que, de certa forma, A llusão Cômica possa ser considerada um "drama da vida" antes da hora (o drama de Pridamant em busca de tempo tanto quanto de seu filho perdido), essa contém fragmentos de um "drama na vida" historicamente datado (peça dentro da peça), daí a dificuldade do trabalho dramatúrgico como de encenação, que deve, buscando "seu valor de presentificação que faz parte de qualquer representação" (Ibid.), encontrar o ponto incandescente desta peça para um espectador hoje, sem pretender ignorar que ela não acaba de ser escrita - colocando sob seus olhos uma ficção e personagens obsoletos e improváveis, o que equivale a colocar em abismo (e à prova) sua própria descrença. $A$ Ilusão Cômica não é uma peça escrita para a cena pós-dramática. Ela é mesmo o oposto. E sem um tensionamento do que ela é historicamente (uma reflexão sobre o drama e a ilusão) e espectadores que somos no início do século XXI, tomados por outro regime teatral, ela pode simplesmente não funcionar.

$O$ que acabei de afirmar sobre o caso exemplar (por causa de sua natureza) de $A$ Ilusão Cômica vale, penso, para qualquer trabalho dramatúrgico hoje. Sempre foi assim (desde a invenção da encenação), já que

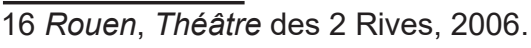


sempre foi uma questão de ler uma peça a partir de nossos dias, entregá-la a espectadores que são nossos contemporâneos - exceto que a ruptura aberta pela invenção da encenação foi agravada por outra, da qual falamos acima: mais do que uma ruptura, uma falha que se liga a uma grande lacuna.

Parece-me que a encenação europeia dos anos de 2010, quando ainda se aplica a peças previamente escritas e a fortiori a clássicos, está construída nessa grande lacuna. Pense em como Thomas Ostermeier nos coloca no mesmo nível de Hedda Gabler de Ibsen $^{17}$ por uma atualização cuja base é dada pela tradução reescrita de Marius von Mayenburg, na qual um dos principais efeitos é substituir o manuscrito de Løvborg jogado por Hedda nas chamas por um ato eminentemente performativo: a destruição real, de um computador portátil. Aqui também, a dramaturgia é inseparável do gesto de encenação: direção dos atores, que parecem não compor, figurinos atuais, cenografia permitindo que os bastidores sejam vistos por um jogo de câmeras de vigilância, breve utilização da imagem filmada no início de cada ato para "entrar neste mundo", que acaba sendo o nosso... Tudo isso sem que em nenhum momento seja ignorada ou negada a dramaturgia interna da peça.

O mesmo problema de adequação à cena atual se coloca de maneira grave para o autor dramático. É certo que esse pode, como costumava fazer, delegá-lo ao "segundo tempo" da arte teatral e, portanto, ao diretor. Essa posição não é mais viável, de início pela razão que dissemos: o teatro é cada vez menos uma "arte em dois tempos" e a relação de união entre um autor e um diretor não ocupa mais a posição dominante que tinha no século $X X$.

O dramaturgo é colocado diante de uma alternativa hoje. O primeiro caminho é

17 Criada en 2005 no Schaubühne, em Berlim. escolhido por um número crescente de autores, que se tornam diretores. Eles fazem isso algumas vezes mantendo os dois tempos tradicionais do teatro (eles escrevem uma peça sem necessariamente pensar em sua encenação e depois a montam). Eles podem fazer isso também fundindo esses dois tempos, como Joël Pommerat, que não concebe de outra forma sua obra de autor dramático, como ele pratica há quase vinte e cinco anos: "Acho hoje que somente se torna verdadeiramente um autor de teatro aproximando fortemente o trabalho de escrita do texto com o trabalho de encenação. / Acho que é um erro conceber esses dois tempos naturalmente separados um do outro." (POMMERAT, 2007, p. 15) Essa posição teórica (substanciada em Pommerat por uma crítica ao poder do diretor, comprovada ao longo do século $X X)$, embora possa abranger práticas muito diferentes, é encontrada através de abordagens de criadores eles mesmos tão diferentes, como Romeo Castellucci, Robert Lepage, François Tanguy, Angelica Liddell, Rodrigo Garcia e muitos outros. Nesses autores, o texto (voluntariamente não dramático) é apenas um elemento (em uma hierarquia que pode variar) entre todos os que compõem a partitura cênica. Além disso, vários deles são artistas visuais de formação, que estão, explicitamente ou não, na filiação de um Robert Wilson ou de um Tadeusz Kantor. Esse conjunto de fenômenos (escrita mais próxima do palco, não separação do texto e de sua encenação, importância da dimensão plástica) tem necessariamente efeitos sobre a natureza dos textos produzidos, o que constitui uma resposta de facto à questão que nós colocamos ${ }^{18}$.

O segundo caminho é o emprestado pe-

18 Cf. Marion Cousin, L'Auteur en scène : analyse d'un geste théâtral et dramaturgie du texte né de la scène, thèse de doctorat sous la direction de Jean-Pierre Ryngaert, Sorbonne Nouvelle - Paris 3, 2012. 
los autores (eu diria então: os escritores de teatro) que, por escolha (às vezes) ou por necessidade (frequentemente), continuam a escrever longe do palco, produzindo textos únicos (se escreve ainda muitos, como atestam as comissões de leitura) aguardando o palco, e que serão cada vez mais textos em sofrimento, cujo casamento com a cena, por mais que desejem, podem nunca acontecer.

A suposição que eu gostaria de continuar para concluir é que esses textos também precisam estar em fase, desde o seu lugar, que é a escrita dramática em sua autonomia, com o estado atual da cena. Vemos muito bem o que não se encaixa mais nesse estado: fábulas muito aparentes, uma estrutura dramática muito robusta (a palavra "intriga" quase desapareceu do vocabulário dos dramaturgos que escrevem sobre o teatro contemporâneo), personagens... muitos personagens. É mais difícil designar, não tanto o que ainda funciona (e cuja obviedade pode ser necessária), mas por que isso funciona. E tanto melhor: a perspectiva não está aqui para restaurar uma norma que, após o romantismo, o nascimento da encenação moderna acabou por dissolver - especialmente que as direções nas quais essas obras se desenrolam são variadas a ponto de serem contraditórias, integrando na escrita a dimensão interdisciplinar da cena contemporânea em benefício ou não de uma fábula e participando, em graus variados, na desconstrução da mimese, que pode ir até sua quase anulação. Vê-se por que são os próprios fundamentos da arte dramática que se encontram abalados: se é para produzir ações que são antes de tudo cênicas e não se dão como representação de ações, fundando somente ocasionalmente (ou não) um outro lugar, um outro tempo, são novas formas de dramaticidade que se trata de inventar.

$O$ enfraquecimento do personagem foi, durante o século $X X$, um dos principais sin- tomas das críticas à mimese, o que poderia ser chamado de "crise da representação". ${ }^{19}$

Isso leva, na obra de um autor como Jon Fosse, a uma forma de desenho comparável, mutatis mutandis (quer dizer, levando-se em conta que repercute plenamente em suas produções obras dramáticas), a essa que está em questão em relação ao confronto palco-plateia de Inferno: "seres sem qualidades" - você, eu - capturados no drama absolutamente mínimo de uma vida qualquer. Dificilmente um drama, dificilmente personagens.

Esse enfraquecimento culmina em obras que querem ver em cena, como no exemplo dos "quatro atores" de Insulto ao Público, apenas performers sem outra identidade que não as suas próprias. Nem mesmo mais "figuras" 20 , mas instrumentistas. É nesses termos, por exemplo, que o dramaturgo russo Ivan Viripaev fala dos intérpretes de sua peça, Danse "Delhi" (VIRIPAEV, 2010): "Este texto não é" para ser representado", mas para "ser interpretado" à maneira de uma partitura musical. ${ }^{21}$ "Galin Stoev, que o encenou, é ainda mais explícito:" O ator não deve representar o personagem, mas representar "com o personagem", da mesma maneira que um músico toca 'seu instrumento'." (Ibid., p. 22) Pura declaração de intenção do autor (transmitida pelo diretor), defendendo uma maneira de representar sua peça? Certamente não: a estrutura do trabalho é inteiramente comandada por essa escolha; os intérpretes repetem de sequência a sequência uma série de variações que relançam os dados da ação de uma de-

19 Cf. Robert Abirached, La Crise du personnage dans le théâtre moderne, Grasset, 1978 ; e Daniel Bougnioux, La Crise de la représentation, La Découverte, 2006.

20 Jean-Pierre Ryngaert e Julie Sermon trouxeram à luz a passagem do personagem à figura em grande número de escritas contemporâneas.

21 Programa do Théâtre National de la Colline, maio de 2011, p. 6. 
terminada situação ${ }^{22}$. Às vezes, é o recurso a uma ou mais figuras narradoras (ou apresentador, ou o comentador ou o coro) que substituirá a ação representada pela narrativa da ação no presente da "representação". De Daniel Danis (DANIS, 2002) a Biljana Srbljanovic (SRBLJANOVIC, 2008) existem muitos exemplos na literatura dramática contemporânea. E, num registro mais distante do "dramático", as "peças" de Valère Novarina não escondem, sob a profusão de nomes de pseudo-personagens, a única presença do ator-intérprete lutando com a fala?

De um modo mais geral, a mimese será posta em causa sempre que a dramaturgia interna de uma peça exigir a realização de ações realmente realizadas em cena e não representando nada além de si mesmas: uma dança, uma "performance", a execução de uma peça musical. $\mathrm{Na}$ minha própria peça, Sob a tela silenciosa (DANAN, 2002) é a ação de fotografar que tinha essa função, o estúdio do fotógrafo lutando com seu modelo e então coincidindo com o espaço cênico, no tempo real da representação. Mas seria necessário evocar obras ainda mais singulares, como Ataques à sua vida de Martin Crimp (colocando em crise sistemática qualquer representação) ou 4.48 Psicose de Sarah Kane (colocando em jogo a vida de seu autor, até seu fim), e muitas outras que, de várias formas e em graus variados, constituem respostas aos transtornos da cena pelos quais começamos este artigo (ou, melhor, participamos nele), testemunhando a vitalidade de escritas que persistiriam em querer dar à luz, talvez não aos dramas, mas a dramas.

22 Para um desenvolvimento mais completo sobre essa peça e, mais amplamente, sobre a problemática desse artigo, eu me permito referir a J. Danan, Entre théâtre et performance : la question du texte, Actes Sud - Papiers, "Apprendre", 2013.
Referências

ABIRACHED, Robert. LaCrisedupersonnage dans le théâtre moderne, Grasset, 1978.

ARTAUD, Antonin. Le Théâtre et son double, in CEuvrescomplètes, t.IV, Gallimard, 1964.

BARBERIS, Isabelle. Théâtres contemporains. Mythes et idéologies, PUF, 2010.

BIET, Christian Biet; FRANTZ, Pierre. "Le théâtre sans l'illusion", Critique, n 699700, août-septembre 2005.

BOUGNIOUX, Daniel. La Crise de la représentation, La Découverte, 2006.

CHEVALLIER, Jean-Frédéric. "Le geste théâtral contemporain : entre présentation et symboles", L'Annuaire théâtral. Revue québécoise d'études théâtrales, $n^{\circ} 36$, automne 2004. "Le geste théâtral contemporain", Frictions, $n^{\circ} 10$, automne-hiver 2006.

CORNEILLE, Pierre; DANAN, Joseph (Direction de l'ouvrage). L'lllusion comique / Dramaturgies de l'lllusion. Publications des Universités de Rouen et du Havre, 2006.

COUSIN, Marion Cousin. L'Auteur en scène : analyse d'un geste théâtral et dramaturgie du texte né de la scène, thèse de doctorat sous la direction de Jean-Pierre Ryngaert, Sorbonne Nouvelle - Paris 3, 2012.

DANAN, Joseph. "Du mouvement comme forme moderne de l'action dans deux pièces d'Ibsen", Etudes théâtrales, n 15-16 / 1999. 
Entre théâtre et performance: la question du texte. Actes Sud - Papiers, "Apprendre", 2013.

Qu'est-ce que la dramaturgie?, Actes Sud - Papiers, "Apprendre", 2010.

Sous l'écran silencieux. Lansman, 2002. , "Témoins d'une présence", Etudes théâtrales, n 51-52 / 2011.

DANIS, Daniel. Terre océane. roman-dit. L'Arche, 2006.

DORT, Bernard. "L'état d'esprit dramaturgique", Théâtre/Public, n 67 , janvier-février 1986.

GOUHIER, Henri. Le Théâtre et les arts à deux temps, Flammarion, 1989.

HANDKE, Peter. Outrage au public, trad. J. Sigrid, L'Arche, 1968.

HURET, Jules. Enquête sur l'évolution littéraire [1891]. Thot, 1982.

POMMERAT, Joël. Théâtres en présence. Actes Sud - Papiers, "Apprendre", 2007.

NANCY, Jean-Luc. Le Sens du monde, Galillé, 1993.

SARRAZAC, Jean-Pierre. Poétique du drame moderne, Seuil, 2012.

SRBLJANOVIC, Biljana. Barbelo, à propos de chiens et d'enfants, trad. G. Keller. L'Arche, 2008.
VIRIPAEV, Ivan. Danse "Delhi", trad. Tania Moguilevskaia et Gilles Morel, Les Solitaires Intempestifs, 2010.

Recebido: 30/09/2019 Aprovado: 01/12/2019 